\title{
Biosynthesis and Characterization of Nickel Nanoparticle Using Ocimum sanctum (Tulsi) Leaf Extract
}

\author{
S. R. KUCHEKAR ${ }^{1}$, P. M. DHAGE ${ }^{1}$, V. B. GAIKWAD ${ }^{2}$, H. R. AHER ${ }^{3 *}$ and S. H. HAN \\ ${ }^{1}$ Women's College of Home Science and BCA, Loni, At/Po. Loni(kd), Tal. Rahata, Dist. \\ Ahmednagar, Maharashtra State- 413713, India \\ ${ }^{2}$ KTHM College, Nashik, MS, India \\ ${ }^{3}$ Department of Chemistry' P.V.P. College, Pravaranagar, India \\ ${ }^{4}$ Inorganic Nanomaterial Laboratory, Department of Chemistry, Hanyang University, \\ Seoul 133-791, South-Korea \\ shashi17@gmail.com
}

Received 2 May 2018 / Accepted 20 May 2018

\begin{abstract}
Nickel nanoparticles were synthesized by biosynthesis method with the help ocimum sanctum leaf extract. The properties of nickel nanoparticles were characterized by using various techniques viz. UV-Visible spectrophotometer, Fourier transform infrared spectrometry(FTIR) and scanning electron microscopy(SEM) coupled with energy dispersive micro analysis(EDAX) and XRD. The spectroscopic methods confirmed the formation of nickel nanoparticles and the microscopic technique confirmed the shape and size of the nickel nanoparticles as spherical. Antibacterial activity of the synthesized nanoparticles was measured by zone inhibition method. The nickel nanoparticles showed effective antibacterial activity against human pathogenic bacteria such as Pseudomonas, Aeruginosa and Escherichia coli. The usage of plant extract for the biosynthesis of nickel nanoparticle makes the process cost effective, non-hazardous and green method.
\end{abstract}

Keywords: Nickel nanoparticles, Ocimum sanctum leaf extract, Biosynthesis

\section{Introduction}

The green synthesis is an eco-friendly pathway for nanoparticle synthesis. The chemical constituents of this herbs includes ursolic acid, eugenol, oleanalic acid, rosmarinic acid, linalool and carvacol. The high eugenol contain in this plant helps to act like a pain killer. These functions are often attributed to tulsi's high content of phenolic compounds and antioxidant properties, with Krishna tulsi (black/purple variety) having a higher phenolic content and antioxidant capacity than white Vana (wild) tulsi ${ }^{1}$. Synthesis of metal nanoparticles has gained significant interest in last twenty years because of their unusual properties and 
prospective applications in optical, electronic, catalytic, magnetic materials, thermal properties with corresponding bulk metals. A number of methods have been developed for the preparation of metal nanoparticles such as photo catalytic reduction, radiolytic reduction, solvent extraction reduction, micro emulsion technique, polyol process and alcohol reduction ${ }^{2}$. In recent years there is an emerging interest to synthesize magnetic nanoparticles of $\mathrm{Fe}, \mathrm{Co}$ and $\mathrm{Ni}$ due to their superior magnetic properties and potential uses in many fields including catalysis, memory storage devices and sensors. In the field of medicine they are used for magnetically controlled drug delivery, magnetic resonance imaging and hyperthermia treatment of cancer cells ${ }^{3-5}$. Many physical and chemical methods including co-precipitation $^{6}$, sol-gel ${ }^{7}$, microemulsion $^{8}$, hydrothermal reaction ${ }^{9}$, electrospray synthesis ${ }^{10}$, and laser ablation ${ }^{11}$ are used to synthesize nanoparticles. These methods may produce well defined pure nanoparticles but they have low productivity, high cytotoxicity, low antioxidant potential and low antimicrobial activity and are not environmental friendly ${ }^{12}$. They also find environmental applications in the field of adsorption of hazardous dye and inorganic pollutants and thus play a vital role in the cleanliness of environment ${ }^{13}$. Due to their good antibacterial and anti-inflammatory activities they are used in the field of biomedicine ${ }^{14-26}$.

\section{Experimental}

For the preparation of nickel solution, $5.59 \mathrm{~g}$ of nickel sulphate was dissolved in double distilled water and made up to $250 \mathrm{~mL}$.

\section{Preparation of leaf extract (Ocimum sanctum)}

Exactly $5 \mathrm{~g}$ of fresh ocimum sanctum leaves were taken in clean beaker, and then washed thoroughly with doubled distilled water. The leaves were dried on filter paper to remove the excess water then $100 \mathrm{~mL}$ distilled water was added by using measuring cylinder and boiled to get leaf extract. It was stored in umber colour bottle and kept in refrigerator.

\section{Synthesis of nickel nanoparticles}

1-2 $\mathrm{mL}$ of $5 \mathrm{mg} / \mathrm{mL}$ nickel solution was added in a round bottom flask then $20 \mathrm{~mL}$ of osmium sanctum leaf extract was added with constant stirring again $100 \mathrm{~mL}$ of nickel solution $(5 \mathrm{mg} / \mathrm{mL})$ was added the brown colour was observed which indicates the formation of nickel nanoparticles (Figure 1). Then synthesized nickel nanoparticles were characterized by UV-Visible spectroscopy. The resulting solution is centrifuged for $20 \mathrm{mins}$ at $5000 \mathrm{rpm}$, centrifugate of aqueous layer was discarded. The residue obtained was removed with little amount of distilled water. Then it was kept for removal of water in plane surface glass dish, these particles were analyzed using FT-IR, XRD, SEM and Edax.

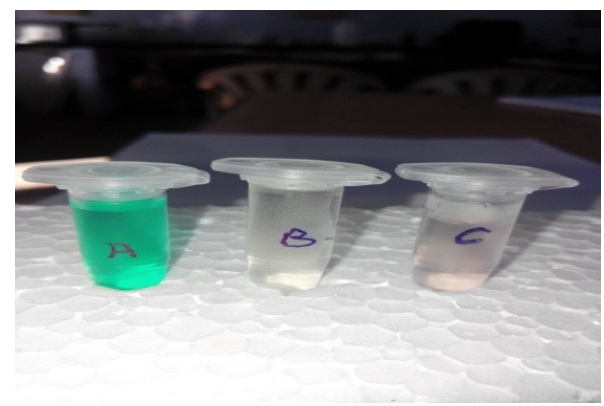

Figure 1. Synthesis of nickel nanoparticle A-Std Ni solution, B- Leaf extract, C- Ni solution + Leaf extract 


\section{Results and Discussion}

\section{$U V$-Visible spectra}

UV-Visible spectra of colloidal nickel nanoparticle shown in Figure 2. It shows well defined surface Plasmon resonance at about $656 \mathrm{~nm}$. The UV-Visible spectra also show that particle are uniformly distributed and round in nature. The SPR characteristic peak is due to oscillation of conduction band electron of nickel. The broadening of peak is due to wide size distribution in solution. The nickel nanoparticle suspended in water and UV-Visible peak of this solution was observed at $656 \mathrm{~nm}$ wavelength. The position and shape of Plasmon absorption of nobel metal nano cluster is strongly dependant on size, shape, dielectric medium, surface absorbed species and surrounding matrix.

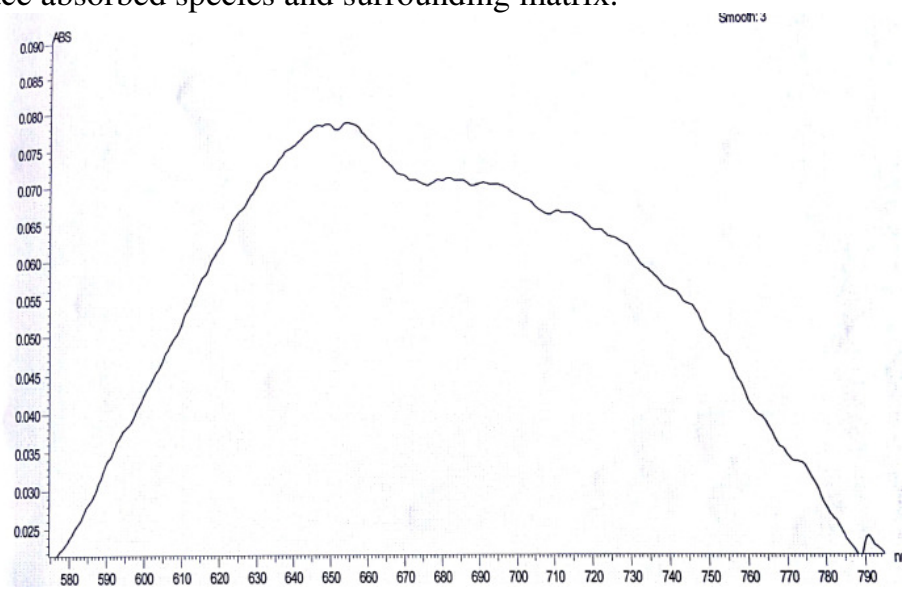

FT-IR

Figure 2. UV-Vis spectra of synthesis Ni-nanoparticle

The result of FT-IR analysis of nickel particles is depicted in Figure 3a. The spectra of nickel particles showed transmission peak at 3500, 2500, 1700, 1150 and $1100 \mathrm{~cm}^{-1}$. The peak at 1100 indicate saturated alkanes, the peak at 1150 indicate alcohol, phenol. The peak at 1700 indicates amide, the peak 2500 indicates carboxylic acid, the peak at 3500 indicates the hydrogen bonded alcohol and phenol. Figure $3 \mathrm{~b}$ shows that the FT-IR spectra of biosynthesized nickel nanoparticles and carried out to identify the possible interaction between protein and nickel nanoparticles. The result of FT-IR study showed sharp absorption peak located at 1100 and $3500 \mathrm{~cm}^{-1}$.
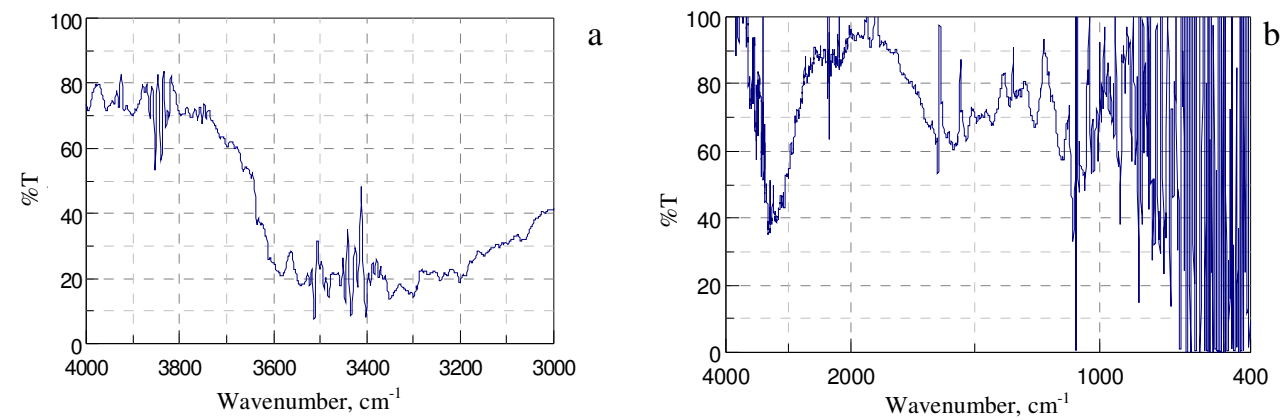

Figure 3. FT- IR spectra of (a) nicke particles (b) nickel nanoparticle 


\section{XRD analysis}

Analysis through x-ray diffraction was carried out to confirm the crystalline nature of nickel nanoparticles. The dry powders of nickel nanoparticles were used for XRD analysis (Figure 4). The diffracted intensities were recorded from 20 to $80{ }^{\circ} \mathrm{C}$ at $2 \Theta$ angles. The comparison of our XRD spectrum with the standard confirmed that nickel nanoparticles form were in the form of nano crystals as different diffraction lines were observed at $2 \Theta$ angle 15, 16, 24.5 and 26 respectively. The average particles size of the nickel nanoparticles synthesized by present bio synthesis method can be calculated by using Debye-Scherer's equation, the average particle size of synthesized nickel nanoparticle is $4.5 \mathrm{~nm}$.

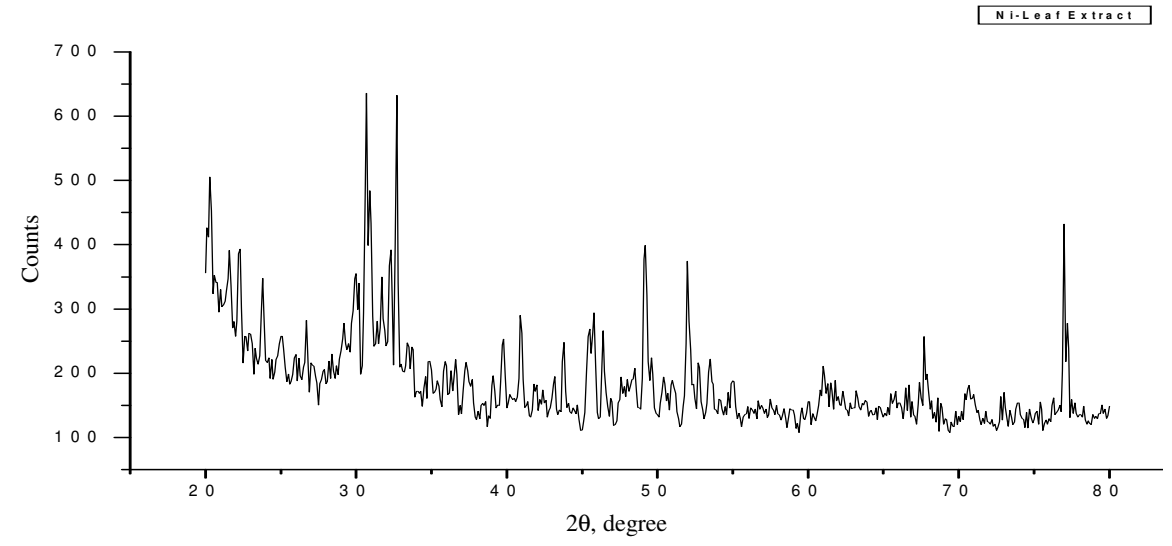

Figure 4. XRD image for nickel nanoparticle

\section{SEM-EDAX analysis}

SEM analysis provided the morphology and size details of the nanoparticles. Figure 5 shows that high density of nanoparticles synthesized by plant extract of ocimum sanctum, the interaction such as hydrogen bonding and electrostatic interaction between the bioorganic capable to form molecular bond is a reason for synthesis of nickel nanoparticles using plant extract. The nickel nanoparticles are rectangular, trigonal and spherical in shape with uniform distribution. However the average size of an individual particle is estimated to be $20-30 \mu \mathrm{m}$. The quantitative and qualitative analysis of element may be concern in the formation of nickel nanoparticles and were identified by EDAX analysis (Figure 6). Due to the surface Plasmon resonance, the nickel nanoparticles show the absorption peaks of higher counts.

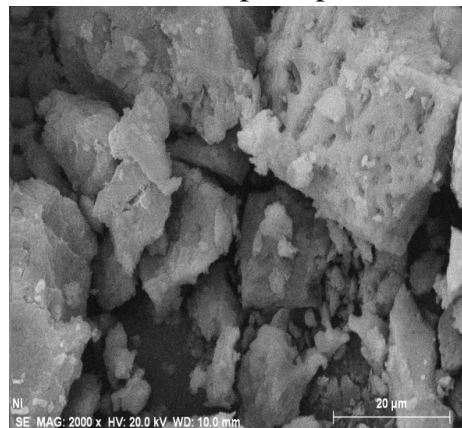

a

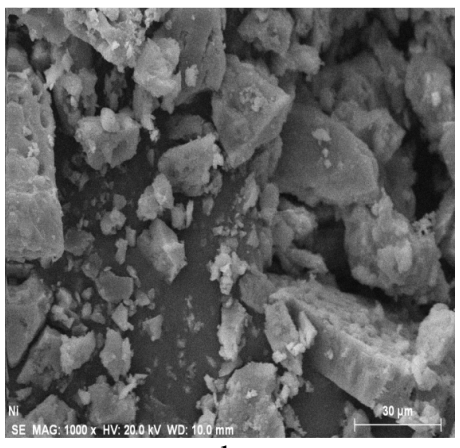

b

Figure 5. SEM image for nickel nanoparticles (a) $20 \mu \mathrm{m}$ and (b) $30 \mu \mathrm{m}$ 


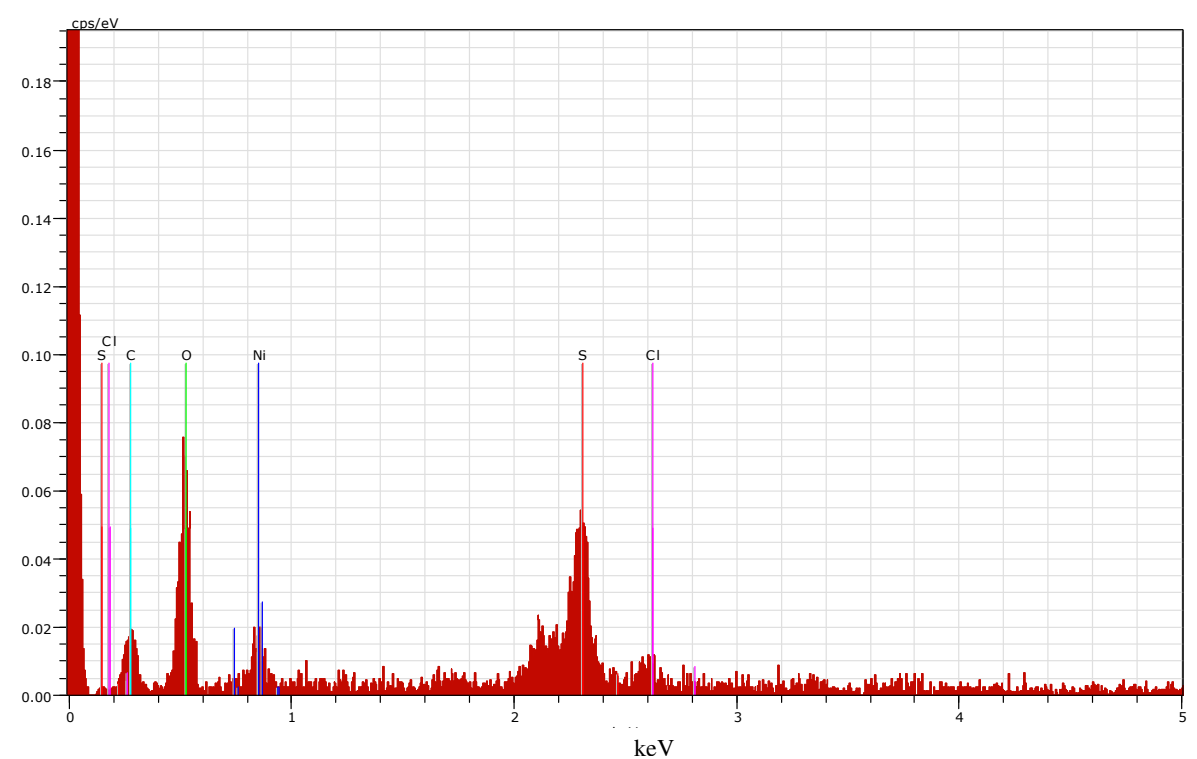

Figure 6. E-DAX image of nickel nanoparticles

Spectrum: Ni

\begin{tabular}{|c|c|c|c|c|c|c|}
\hline El & AN & Series & unn. [wt.\%] & C norm. [wt.\%] & C Atom. [at.\%] & C Error[\%] \\
\hline $\mathrm{O}$ & 8 & K- series & 37.29 & 52.83 & 65.29 & 9.7 \\
\hline $\mathrm{Ni}$ & 28 & K- series & 18.04 & 25.57 & 8.61 & 0.9 \\
\hline $\mathrm{C}$ & 6 & K- series & 8.80 & 12.47 & 20.53 & 4.6 \\
\hline $\mathrm{S}$ & 16 & $\mathrm{~K}$ - series & 5.70 & 8.07 & 4.98 & 0.3 \\
\hline CI & 17 & K- series & 0.75 & 1.06 & 0.59 & 0.1 \\
\hline
\end{tabular}

\section{Antimicrobial activity}

The Figure 7 shows the nanoparticle synthesized from nickel are capable of showing antimicrobial activity against E-coli and Pseudomonas bacteria. The zone of inhibition for these organisms was found to be $2.1 \mathrm{~mm}$ and $1.3 \mathrm{~mm}$ respectively. The synthesized nickel nanoparticles prepared from ocimum sanctum leaf extract showed antimicrobial activity against tridox, curry. However the antimicrobial activity of nickel nanoparticles depends on the type of bacteria along with the size of nickel nanoparticles and also the formation of pits in the cell wall of microorganism. The nickel nanoparticles affects fugus cell by attacking their membrane thus distrusting the membrane potential. The biological synthesized nickel nanoparticles prepared by direct reduction method showed antimicrobial activity against $E$-coli and pseudomonas. The highest antimicrobial activity was observed against curry and tridox.
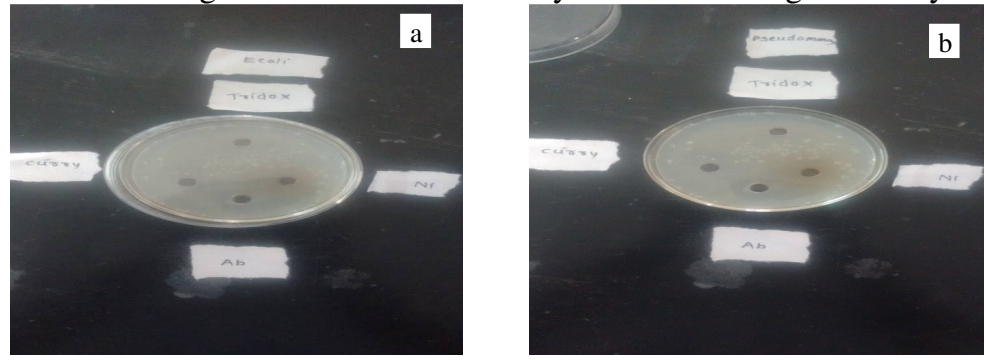

Figure 7. Antimicrobial activity of nickel nanoparticle (a) E-coli and (b) Pseudomonas 


\section{Conclusion}

In this study simple approach was attempted to obtain a green eco-friendly, non-toxic way for synthesis of nickel nanoparticle. The primary confirmation for nickel nanoparticle was due to colour changes and UV/Vis absorption spectra of nickel nanoparticles formed peak at $656 \mathrm{~nm}$. The SEM study was identified that the shape of nickel nanoparticle appeared like irregular spherical shape with rough surface. Edax study was to find out percentage of nickel, oxygen, carbon and chlorine antimicrobial activity of nickel nanoparticle shows better zone of inhibition against two bacterial pathogens i.e. Pseudomonas and E.coli. Green synthesis method is rapid, convenient and less time consuming environmentally safe method for the synthesis of nickel nanoparticles.

\section{Acknowledgment}

Authors are thankful to the management PRESS, Loni for providing necessary facilities in department.

\section{References}

1. Wangcharoen W and Morasuk W, J Sci Technol., 2007, 29(5), 1407-1415.

2. Chen D and Hsieh C, J Mater Chem., 2002, 12, 2412-2415; DOI:10.1039/B200603K

3. Rui H, Xing R, Xu Z, Hou Y, Goo S and Sun S, Adv Mater., 2010, 22, 2729-2742; DOI:10.1002/adma.201000260

4. Brigger I, Dubernet C and Couvreur P, Adv Drug Delivery Rev., 2002, 54(5), 631651; DOI:10.1016/S0169-409X(02)00044-3

5. Gupta A. K and Gupta M, Biomaterials, 2005, 26(13), 1565-1573; DOI:10.1016/j.biomaterials.2004.05.022

6. Petcharoen K and Sirivat A, Mate Sci Engg B: Solid-State Materials Adv Technol., 2012, 177(5), 421-427; DOI:10.1016/j.mseb.2012.01.003

7. Jia F L, Zhang L Z, Shang X Y and Yangv Y, Adv Mater., 2008, 20, 1050-1054; DOI:10.1002/adma.200702159

8. Chen D H and Wu S H, Chem Mater., 2000, 12(5), 1354-1360; DOI:10.1021/cm991167y

9. Chen D and Xu R, J Solid State Chem., 1998, 137(2), 185-190; DOI:10.1006/jssc.1997.7631

10. Basak S, Chen D R and Biswas P, Chem Engg Sci., 2007, 62(4), 1263-1268; DOI:10.1016/j.ces.2006.11.029

11. Yang G W, Prog Mater Sci, 2007, 52(4), 648-698; DOI:10.1016/j.pmatsci.2006.10.016

12. Nagaraj B, Krishnamurthy N B, Liny P, Divya T K and Dinesh R, Int J Pharma Bio Sci., 2011, 2, 557-565.

13. Pandian C J, Palanivel R and Dhananasekaran S, Chine J Chem Engg., 2015, 23(8), 1307-1315; DOI:10.1016/j.cjche.2015.05.012

14. Sudhasree S, Shakila Banu A, Brindha P and Kurian G A, Toxicological Environ Chem., 2014, 96(5), 743-754; DOI:10.1080/02772248.2014.923148

15. Krishnamurthy N, Vallinayagam P and Madhavan D, Engineering Chemistry, PHI Learning Pvt. Ltd, 2014.

16. Hyeon T, Chem Commun., 2003, 9, 927-934; DOI:10.1039/B207789B

17. Karmhag R, Tesfamichael T, Wackelgard E, Niklasson G A and Nygren M, Solar Energy., 2000, 68(8), 329-333; DOI:10.1016/S0038-092X(00)00025-6 
18. Mariam A A, Kashif M, Arokiyaraj S, Bououdina M, Sankaracharyulu M G V, Jayachandran M and Hashim U, Dig J Nanomater Biostruct., 2014, 9(3), 1007-1019.

19. Saxena A, Kumar A and Mozumdar S, J Mole Catal A: Chem., 2007, 269(1-2), 35-40; DOI:10.1016/j.molcata.2006.12.042

20. Alonso F, Riente $\mathrm{P}$ and Yus M, Tetrahedron, 2008, 64(8), 1847-1852; DOI:10.1016/j.tet.2007.11.093

21. Dhakshinamoorthy A and Pitchumani K, Tetrahedron Lett., 2008, 49(11), 1818-1823; DOI:10.1016/j.tetlet.2008.01.061

22. Alonso F, Riente P and Yus M, Eur J Organic Chem., 2009, 2009, 6034-6042; DOI:10.1002/ejoc.200900951

23. Alonso F, Riente P and Yus M, Eur J Org Chem., 2008, 2008, 4908-4914; DOI:10.1002/ejoc.200800729

24. Li X K, Ji W J, Zhao J, Wang S J and Au C T, J Catal., 2005, 236(2), 181-189; DOI:10.1016/j.jcat.2005.09.030

26. Li Y, Zhang B, Xie X, Liu J, Xu Y and Shen W, J Catal., 2006, 238(2), 412-424; DOI:10.1016/j.jcat.2005.12.027 